\title{
ESPANHOLISMOS NO LÉXICO DO BRASIL CENTRAL: CONTRIBUIÇÕES DO PROJETO ALIB
}

\author{
SPANISHNESSES IN THE LEXICON OF MIDWESTERN BRAZIL: CONTRIBUTIONS \\ OF THE ALIB PROJECT
}

\author{
Daniela de Souza Silva Costa \\ Professora da Universidade Estadual de Mato Grosso do Sul \\ danielassilva@hotmail.com \\ Aparecida Negri Isquerdo \\ Professora da Universidade Federal de Mato Grosso do Sul \\ anegri.isquerdo@terra.com.br
}

\begin{abstract}
RESUMO: Este trabalho discute a presença de unidades léxicas de base espanhola no falar da região Centro-Oeste do Brasil documentadas pelo Projeto Atlas Linguístico do Brasil, com vistas a verificar em que proporção a proximidade geográfica, histórica e cultural dos habitantes dessa região com populações provenientes de países de língua espanhola deixa vestígios no léxico. Orientando-se principalmente pelos princípios da Dialetologia, da Geolinguística e da Lexicologia, evidenciaram-se, nos dados empíricos, traços de influência espanhola na região, por meio do uso de espanholismos para designar elementos da fauna, revelando que tal influência reflete-se não somente na dança, na alimentação e nos hábitos, mas também no léxico, objeto deste estudo.

PALAVRAS-CHAVE: Léxico; Centro-Oeste; Espanholismos; Projeto ALiB.
\end{abstract}

ABSTRACT: This paper discusses the presence of Spanish lexical units in the speaking of Midwestern Brazil, as documented by the Brazilian Linguistic Atlas Project (ALiB), in order to verify to what extent the geographical proximity, history and culture of the inhabitants of this region with populations from Spanish speaking countries leave traces in the lexicon. Guided primarily by principles of Dialectology, Geolinguistics and Lexicology, there were found, in the empirical data, traces of Spanish influence in that region, through the use of Spanishnesses to designate elements of fauna, revealing that such influence is reflected not only in dance, food and habits, but also in the lexicon, the object of this study.

KEYWORDS: Lexicon; Midwestern Brazil; Spanishnesses; ALiB project.

\section{INTRODUÇÃO}

A linguagem humana representa muito mais que o conjunto de signos utilizados para a comunicação; expressa também aspectos do pensar do povo que a utiliza. A necessidade de o homem se comunicar, externar pensamentos e eternizar sua existência, por meio da transmissão de seus hábitos e tradições, motiva o uso da língua de formas distintas, considerando-se que o sistema linguístico "[...] traduz o mundo e a realidade social segundo o seu próprio modelo, refletindo uma cosmovisão que lhe é própria, expressa nas suas categorias gramaticais e léxicas..." (BIDERMAN, 1978, p.80).

Assim, particularizando-se de acordo com a sociedade em que está inserida, a língua reflete aspectos da identidade de um grupo, uma vez que exprime suas ideias e retrata aspectos da 
sua realidade. Nesse sentido, uma língua transplantada ${ }^{1}$ certamente sofre alterações, influências e adequações, desenhando-se de acordo com as necessidades de seus usuários.

Essas mudanças linguísticas são percebidas especialmente no nível lexical, repertório vocabular de um grupo de falantes utilizado para nomear seu ambiente físico e social, razão por que o léxico é considerado o nível da língua que reflete com mais intensidade as alterações por que passa uma sociedade. Assim, as mudanças no âmbito do léxico são influenciadas não apenas por condicionantes linguísticos, mas também (e principalmente) por fatores extralinguísticos, como os contatos interétnicos e contingências socioeconômicas e geográficas, por exemplo, o que pode, inclusive, provocar o surgimento de diferentes normas lexicais em uso pelos grupos sociais.

O conceito de norma, em linguística, foi primeiramente estudado por Hjelmslev, segundo o qual ela seria a "forma material [da língua], definida por una realización social dada, pero independentemente todavia del detalle de la manifestación ${ }^{2 "}$ (HJELMSLEV, 1943 apud LARA, 1976, p.38). Após as pesquisas do linguista dinamarquês, Eugênio Coseriu sistematizou o estudo da norma definindo-a como aquela que "abrange fatos linguísticos efetivamente realizados e existentes na tradição" (COSERIU, 1980, p. 123). Em outras palavras, a norma é a porção realizada do sistema linguístico, posta em prática pelos falantes e, por esse mesmo motivo, reflexo das mudanças por que passam as sociedades.

E a questão da variedade brasileira do português pode ser vista sob essa perspectiva de mudança. A língua do colonizador, quando transplantada para o Brasil ainda no início do período colonial (século XVI), mostrava-se, em determinados aspectos, insuficiente para designar a diversidade de elementos da nova realidade - grandes matas fechadas, animais selvagens, hábitos desconhecidos, sobretudo os relacionados às práticas culturais das nações indígenas antes nunca vistas, o que acabou por ocasionar a necessidade da utilização de palavras do léxico das línguas indígenas, em especial do tupi, para a nomeação desses elementos. Assim, a partir dessa realidade linguística que se instaurou no novo território, começou a se desenhar a norma lexical brasileira, que acolheu empréstimos linguísticos de diversos estratos:

[...] o sistema lexical brasileiro registra, em sua configuração linguística, uma simbiose de estratos de comunicação, pertencentes a três grupos étnicos demarcados [...] portugueses, indígenas e africanos, convivendo no país, desde os séculos iniciais da conquista (DICK, 2000, p. 296).

Além da influência das matrizes étnicas indígena e africana, outras etnias também contribuíram e continuam a contribuir para a consolidação da norma lexical do português brasileiro, uma vez que, desde o período colonial, diferentes povos têm vindo para o Brasil em busca de melhores condições de vida, como os imigrantes espanhóis, italianos, alemães, poloneses, japoneses, árabes, libaneses, por exemplo, além das populações advindas de outros países da América do Sul, falantes do idioma espanhol.

\footnotetext{
${ }^{1}$ Denomina-se, aqui, língua transplantada aquela que é produto da colonização, trazida da metrópole para a colônia.

2“A forma material, definida por uma realização social dada, mas independente, porém, do detalhe da manifestação" (TN = tradução nossa).
} 
E esse trânsito de populações de língua espanhola em território nacional é sobremaneira influenciado pela facilidade de acesso desses povos ao Brasil. Nesse contexto, devem-se considerar especialmente as fronteiras secas entre o Brasil e alguns países da América espanhola, como a Bolívia e o Paraguai, que fazem divisa com a região Centro-Oeste do Brasil e que favorecem trocas linguísticas e culturais entre os habitantes dessas áreas geográficas. Isso propicia uma vasta riqueza cultural à medida que aproxima línguas, costumes, tradições, enfim, hábitos culturais intercambiáveis entre esses espaços fronteiriços e que, por extensão, refletem-se na norma lexical, especialmente em regiões em que esse contato ocorre com maior frequência e intensidade.

Este artigo discute a questão da presença de unidades lexicais de base espanhola no léxico de habitantes dos três Estados da região Centro-Oeste ${ }^{3}$, tomando-se como corpus de estudo dados geolinguísticos documentados por meio de inquéritos linguísticos realizados pelos pesquisadores do Projeto Atlas Linguístico do Brasil (Projeto ALiB), área semântica da fauna (questões 64 a 88 do Questionário Semântico-lexical do Projeto ALiB) no universo geográfico selecionado para este estudo. Foram analisadas as respostas fornecidas pelos 80 informantes distribuídos por 20 localidades da rede de pontos $\mathrm{ALiB}^{4}$ do interior da região Centro-Oeste - Mato Grosso: Poxoréu, Cáceres, Diamantino, Alto Araguaia, Barra do Garças, Aripuanã e Vila Bela da Santíssima Trindade; Mato Grosso do Sul: Corumbá, Ponta Porã, Nioaque, Paranaíba e Coxim; Goiás: Jataí, Quirinópolis, Goiás, Formosa, Porangatu, São Domingos, Aruanã e Catalão. Os informantes foram selecionados de acordo com o perfil definido pelo Comitê Nacional de coordenação do Projeto ALiB: nascidos e criados na localidade pesquisada, de duas faixas etárias (18 a 30 anos e 50 a 65 anos), sexos masculino e feminino e com escolaridade de no máximo o Ensino Fundamental ${ }^{5}$.

Este estudo buscou investigar em que proporção o repertório vocabular dos habitantes das cidades pesquisadas é influenciado pelas trocas culturais entre brasileiros e falantes da língua espanhola, além de buscar possíveis motivações para a manutenção e/ou desaparecimento desse substrato na língua em uso por essa parcela da população brasileira.

Para tanto, foram analisadas as 149 respostas fornecidas pelos informantes dos três Estados supracitados para as perguntas selecionadas para o estudo, sob as perspectivas léxicosemântica e diatópica. A identificação das unidades de base espanhola foi pautada na consulta a dicionários gerais de língua portuguesa contemporânea - Houaiss (2001) e Ferreira (2004), dicionários etimológicos da língua portuguesa - Cunha (1982, 2010) e Machado (1987), além de dicionários de língua espanhola de diferentes momentos históricos - García (1943), Cavero (1977), Dicionário da Real Academia Espanhola (2001) e Corominas (1998). A consulta a esses dicionários permitiu a identificação da base linguística das variantes e, consequentemente, a seleção dos itens léxicos de origem espanhola. A análise foi orientada por princípios teórico-metodológicos da Lexicologia, da Geolinguística e da Dialetologia.

\section{O BRASIL CENTRAL: UM POUCO DE SUA HISTÓRIA E IDENTIDADE}

\footnotetext{
${ }^{3}$ Uma primeira versão deste trabalho foi apresentada em forma de comunicação oral no VI Congresso Brasileiro de Hispanistas e II Congresso Internacional da Associação Brasileira de Hispanistas, realizados no período de 31 de agosto a 03 de setembro de 2010, na Universidade Anhanguera/UNIDERP, Campo Grande - MS.

${ }^{4} \mathrm{O}$ Projeto ALiB possui uma rede de pontos de 250 localidades, distribuídas por todos os Estados da Federação. ${ }^{5}$ Em todas as localidades, foram entrevistados 04 informantes de Ensino Fundamental, distribuídos segundo as variáveis sexo, idade, naturalidade. Nas capitais, além dessa estratificação, foram entrevistados mais 04 informantes, também estratificados quanto ao sexo, idade e naturalidade, mas com escolaridade superior.
} 
Sabe-se que, à época do Descobrimento (século XVI), a região Centro-Oeste era habitada por populações indígenas de diversas etnias, como os Guató, Guaycuru e Terena, Paiaguá, Guarani e Caiuá (SIGRIST, 2000, p.38), por exemplo, além de ser ainda território espanhol, pelo acordado entre as potências do século XVI, Espanha e Portugal, por meio do Tratado de Tordesilhas (1494-1750).

A primazia espanhola também vigorava no Brasil Central, uma vez que, pelo mesmo Tratado, as terras de Mato Grosso do Sul, Mato Grosso e parte de Goiás integravam "[...] oficialmente a Província do Paraguai até 1750, quando mudaram para o domínio de Portugal, conforme um novo acordo de limites, o Tratado de Madri, firmado entre Espanha e Portugal..." (GRESSLER et al., 2005, p.47). Porém, pelo acordado nesse Tratado, apenas parte do atual território brasileiro passou para o domínio português, ficando as demais terras da América do Sul ainda sob a regência da Coroa espanhola, fator que fez com que os países sul-americanos, à exceção do Brasil, mantivessem as características dos colonizadores espanhóis.

Dessa maneira, a história compartilhada entre espanhóis e portugueses no território do atual Centro-Oeste brasileiro manteve a proximidade entre as nações, seja pelos hábitos culturais, seja pela língua em uso, que muitas vezes recebe influências de seus vizinhos, tanto a língua portuguesa com marcas das línguas hispânicas, como o espanhol platino refletindo marcas portuguesas. Assim, essa proximidade entre os países de língua espanhola e a antiga Colônia portuguesa na América resultou numa marcante presença da cultura espanhola, especialmente em determinadas áreas semânticas, como a alimentação, as crenças, a dança, na formação cultural do povo brasileiro, enfim. E sendo a língua produto cultural, ela também revela esses influxos em seu vocabulário, especialmente pelos empréstimos linguísticos evidenciados nas escolhas lexicais dos falantes. Na região Centro-Oeste, por exemplo, que abriga Estados que fazem divisa seca com o Paraguai e a Bolívia (Mato Grosso do Sul e Mato Grosso), essa presença é bastante acentuada.

Além da questão fronteiriça, há que se considerar, para o entendimento dessa situação de contato, questões político-econômicas que permearam a história do Brasil e do Paraguai, como a Guerra da Tríplice Aliança (1864-1870). Nesse sentido, Santana e Isquerdo (2008, p. 11) acrescentam que, dentre as consequências da disputa bélica, encontra-se a "[...] forte imigração de cidadãos paraguaios para o sul do estado de Mato Grosso do Sul, para o trabalho na exploração da erva-mate...", em busca de melhores condições de vida naquele momento improváveis em seu país natal.

Além disso, ainda na atualidade, a relação entre os povos fronteiriços permanece viva. Em Mato Grosso do Sul, por exemplo, no município de Corumbá, fronteira com a Bolívia, a instalação da feira boliviana na cidade "e do popular shopping-chão em Quijarro/Bolívia" representam um avanço em termos comerciais e culturais (SIGRIST, 2000, p.41). Ainda em Mato Grosso do Sul, em Ponta Porã, a Avenida Internacional marca a divisa entre Brasil e Paraguai, localidade conhecida pelas relações comerciais entre os dois países e pelas frequentes viagens de compras realizadas por sul-mato-grossenses e mesmo habitantes de outros Estados brasileiros para a cidade paraguaia de Pedro Juan Caballero.

Esses contatos deixam marcas na cultura da região Centro-Oeste, em especial na dos Estados de Mato Grosso e Mato Grosso do Sul, que assimilaram muitos hábitos e tradições, sobretudo de origem hispanoamericana, dentre outros setores, destacam-se na música: a polca paraguaia (e suas variações chamamé, rasqueado e guarânia) - dança popular totalmente assimilada 
pelos mato-grossenses e sul-mato-grossenses; e na alimentação: o consumo da chipa - espécie de pão de queijo, de origem paraguaia - e o puchero - tipo de cozido com carnes, vegetais e legumes variados, prato espanhol com adaptações na América hispânica que atravessou fronteiras e se incorporou aos hábitos alimentares dos sul-mato-grossenses.

Nota-se, pelos exemplos citados, que esses contatos interferem também nas escolhas lexicais dos falantes da língua portuguesa dessas áreas de fronteira. Os dados recolhidos pelo Projeto ALiB aqui examinados evidenciam aspectos dessa realidade linguística à medida que reúnem diversos espanholismos em uso na modalidade oral da variante brasileira do português falado no Brasil Central.

\section{ESPANHOLISMOS: ANÁLISE E DISCUSSÃO DOS DADOS}

Dentre as 25 perguntas do Questionário Semântico-lexical do Projeto Atlas Linguístico do Brasil relacionadas à área semântica da fauna, em 07 delas foram registradas unidades léxicas aqui classificadas como espanholismos ${ }^{6}$ : mulata, periquito e catorra (QSL 68 - designativos para "a ave de penas coloridas que, quando presa, pode aprender a falar"); cola (QSL 74 - a "crina da cauda do boi/cavalo"); chifre (QSL 77 - "o que o boi tem na cabeça"); mocho/mucho (QSL 78 e 79 - nomes, respectivamente, para o "boi sem chifre" e para a "cabra sem chifre") e borrachudo e mosquito (QSL 88 - designativos para "aquele inseto pequeno, de perninhas compridas, que canta no ouvido das pessoas, de noite").

Para a análise dos dados, este trabalho foi dividido em duas seções: uma que trata as questões ligadas à Lexicologia, como o estudo etimológico e as questões semânticas, haja vista que a Lexicologia é o ramo das ciências do léxico que estuda a origem e as transformações fonéticas, morfológicas, sintáticas e semânticas das palavras, comparando-as com outras da mesma língua ou de línguas diversas, numa perspectiva sincrônica ou diacrônica. Na segunda parte, reflete-se sobre os dados sob o viés dialetológico, tendo em vista que os dois princípios basilares da Dialetologia são "[...] o reconhecimento das diferenças ou das igualdades que a língua reflete e o estabelecimento das relações entre as diversas manifestações linguísticas documentadas ou entre elas e a ausência de dados registrados, circunscritos a espaços e realidades prefixados..." (CARDOSO, 2010, p. 25).

\subsection{Análise léxico-semântica}

O Gráfico 1 apresenta o montante das 149 unidades léxicas documentadas e a representatividade percentual quanto às línguas de origem:

Gráfico 1 Distribuição das unidades léxicas relacionadas à área semântica da fauna, documentadas pelo ALiB no interior da região Centro-Oeste, segundo a língua de origem

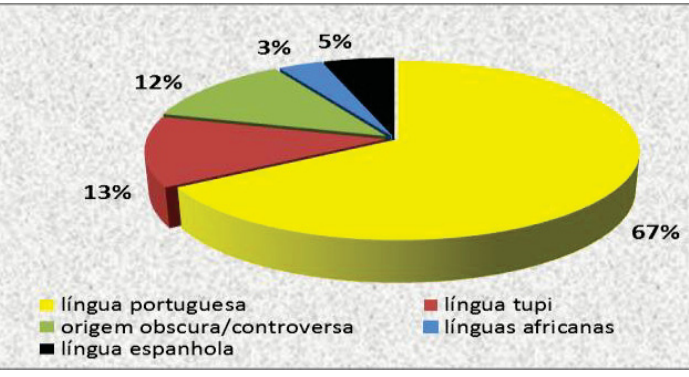

\footnotetext{
6“Palavra, construção ou locução da língua espanhola usada em outra língua” (HOUAISS, 2001).
} 


\section{Fonte: autor}

Alguns dos designativos de origem espanhola já estão incorporados ao léxico da língua portuguesa (mulata, periquito, chifre, mocho/mucho, borrachudo e mosquito), enquanto outros demonstram particularidades regionais (catorra e cola), confirmadas pela consulta às obras lexicográficas pesquisadas.

A análise dessas unidades léxicas, na sequência deste trabalho, foi organizada de acordo com a pergunta do Questionário Semântico-Lexical/ALiB que motivou a documentação das unidades lexicais mencionadas.

2.1.1 Designações para "a ave de penas coloridas que, quando presa, pode aprender a falar" (QSL/68)

Três espanholismos foram citados pelos informantes do Projeto ALiB como designação do conceito em questão: mulata, catorra e periquito.

Segundo Cunha (1982), a unidade lexical mulata advém do étimo castelhano mulato, "filho de pai branco e mãe preta ou vice-versa", acepção compartilhada por Houaiss (2001). Nos dicionários gerais e etimológicos consultados, não foi encontrado o registro de outras acepções que contenham qualquer traço comum entre o mestiço das raças negra e branca e a "ave de penas coloridas que quando presa pode aprender a falar" (QSL 68/ALiB) que pudesse gerar a associação promovida pelos informantes. Todavia, o Dicionário do Brasil Central, de Waldomiro Bariani Ortêncio (1983), confirma o uso regional do termo na acepção em que foi mencionado pelos habitantes dos três Estados da região Centro-Oeste: "1. Nome comum à fêmea do papagaio: 'Dá o pé, mulata'” (ORTÊNCIO, 1983).

Foram ainda realizadas outras pesquisas complementares em fontes específicas na área da Biologia, com o objetivo de apurar possível explicação para o uso de mulata para nomear a ave usualmente designada como papagaio. Para tanto, foi consultado um estudo de Etnobiologia realizado por Saiki, Guido e Cunha $(2009)^{7}$, que registrou o designativo na sua forma simples mulata como nome vernáculo correspondente a três nomes científicos Amazona aestiva, Amazona amazônica, Amazona farinosa ${ }^{8}$, além de quatro formas compostas com a base mulata: mulata cabeça-de-coco e mulata-maracanã, correspondentes ao nome científico Aratinga aurea; mulata beira-rio e mulata cabeça-de-coco, relacionadas ao nome científico Aratinga auricapillus e mulata-enredeira, o nome na língua portuguesa equivalente a Brotogeris chiriri. Essas espécies têm como característica comum o fato de pertencerem à família Psitacidae e fazerem seu ninho em "[...] oco de pau, caixa de joão-de-barro; cupim-deárvore; galho de árvore..." (SAIKI et al., 2009, p. 47)9.

\footnotetext{
${ }^{7}$ Esse artigo discute resultados de pesquisa oral que "investigou o conhecimento local dos moradores dos distritos rurais de Cruzeiro dos Peixotos, Martinésia e Tapuirama (Uberlândia, MG) sobre ecologia, comportamento, taxonomia, nomenclatura e aspectos econômico-culturais dos Psittacidae da região, apontando as concordâncias e discordâncias entre o conhecimento científico e o conhecimento local [...] Amazona aestiva, Ara ararauna, Aratinga aurea, Aratinga leucophthalma, Brotogeris chiriri e Forpus xanthopterygius foram as espécies de Psittacidae mais citadas em todas as etapas do trabalho" (SAIKI et al., 2009, p. 41).

${ }^{8}$ Espécie exótica, segundo Saiki, Guido e Cunha (2009, p.45).

${ }^{9}$ Segundo a mesma pesquisa, os locais de nidificação do Psittacidae, espécie papagaio são os seguintes: "Oco de pau; cupim do chão; coqueiro; árvore alta; paredão" (SAIKI et al., 2009, p. 47).
} 
$\mathrm{Na}$ linguagem corrente da região Centro-Oeste, a variante mulata é utilizada para nomear a fêmea da espécie, daí a expressão "dá o pé, mulata", cristalizada na região, utilizada para atrair a ave para o dedo do interlocutor. A documentação do designativo mulata e suas formas derivadas nessa pesquisa de Etnobiologia realizada também com base em dados da língua oral, em uma região do Triângulo Mineiro, que faz fronteira com Mato Grosso do Sul, associada à certificação do uso da unidade lexical por uma obra lexicográfica sobre o léxico do Brasil Central (ORTÊNCIO, 1983) abalizam o uso regional da unidade lexical mulata também na região Centro-Oeste.

Já periquito, do étimo periquito, nomeia "a ave psitaciforme, da família dos psitacídeos" (MACHADO, 1987). Porém, a associação entre os referentes pode estar ligada à acepção registrada na obra de Cavero (1977) - "pequena ave, semelhante ao papagaio, mas mais pequena" - e referendada em Cunha (1982), cujos registros esclarecem tratar-se do próprio papagaio.

Por fim, catorra, espanholismo também utilizado para nomear o referente conhecido popularmente como "papagaio", está dicionarizado na obra de Houaiss (2001) como "papagaio pequeno". Já o Diccionario da Real Academia Española registra cotorra como "der. regres, de cotorrera, por cotarrera" ${ }^{10,}$, na acepção de "1. f. Papagayo pequeño; 2. f. urraca; 3. f. Ave prensora americana, parecida al papagayo, con las mejillas cubiertas de pluma, alas y cola largas y puntiagudas, y colores varios, en que domina el verde" (RAE, 2001). Pelo exposto, pode-se considerar catorra um empréstimo do espanhol, uma variante de cotorra, designação de uma espécie de papagaio.

Nota-se, pela discussão das três variantes focalizadas (mulata, periquito, catorra), que o falante nem sempre consegue estabelecer a diferença entre as espécies da família dos Psittacidae, em decorrência da pouca familiaridade com esses referentes, haja vista os informantes do ALiB serem do meio urbano, ou ainda pelas similaridades existentes entre essas espécies, como atestam os próprios especialistas da área no trabalho anteriormente mencionado:

[...] Os psitacídeos são aves cuja diagnose é imediata quando comparados a outros grupos, devido às suas características marcantes, como tipo de bico, capacidade de emitir sons semelhantes à fala humana e inteligência apurada. No entanto, as espécies pertencentes à família Psittacidae são muito semelhantes entre si, o que dificulta uma identificação precisa de todas as espécies deste grupo, quer pela morfologia, quer pela vocalização, como identificado no discurso de alguns informantes (SAIKI; GUIDO; CUNHA, 2009, p.44-45).

\subsubsection{Designação para a "crina da cauda do boi/cavalo" (QSL/74)}

O único item lexical de base espanhola documentado para nomear "a crina da cauda" (QSL 74 / ALiB) foi cola. Silva (1813) registra, como terceira acepção do verbete colla, "cauda [...] (do Hespanhol cola)". Já o dicionário de Cunha (1982) considera cola do "castelhano cola, derivado do latim vulgar", na acepção de "cauda". O dicionário da Real Academia Espanhola

\footnotetext{
${ }^{10}$ Cotarrera: "f. coloq. Mujer que andaba de cotarro en cotarro". Cotarro: "coloq. Colectividad en estado de inquietud o agitación” (RAE - Dicionário da Real Academia Española, 2001).
} 
(2001), por sua vez, traz a unidade lexical cola definida na acepção de "extremidad posterior del cuerpo y la columna vertebral de algunos animales".

\subsubsection{Designações para "aquilo que o boi tem na cabeça” (QSL/77)}

Para essa pergunta, foi obtida como resposta apenas a unidade lexical chifre, mencionada por todos os informantes entrevistados. Silva (1813), no verbete chifre, faz remissiva a corno, provavelmente a palavra mais utilizada em Portugal para nomear esse referente no período da história da língua portuguesa coberto pelo dicionário. Nascentes (1961), por sua vez, registra chifre como "do esp. chifle, ant. e leonês, deverbal de chiflar 'assobiar'. Aplicou-se às pontas do boi pelo emprego que delas se faz como trompa ou buzina". Já Machado (1987) registra etimologia duvidosa para a unidade lexical chifre.

Corominas (1998), por seu turno, registra chifle como termo

[...] fin S. XVIII, 'cuerno, especialmente el empleado para contener municiones o líquidos'. Vocablo propio de las hablas leonesas, hispanoamericanas y portuguesas, cuyo significado básico parece haber sido 'tubo' (de donde 'cuerno', por el empleo de éste como tubo) y antes 'silbato'; deriv. de chiflar por silbar (COROMINAS, 1998).

Em síntese, os dados consultados sobre a origem da variante chifre lhe conferem o estatuto de espanholismo, na perspectiva deste estudo.

\subsubsection{Designações para "boi/cabra sem chifre" (QSL/78)}

Também nessa pergunta foi apurado um único espanholismo como resposta, ou seja, mocho e sua variante mucho, unidades lexicais de base castelhana. Corominas (1998) registra:

[...] 1170, 'sin punta' y espte. 'sin cuernos'. Origem incierto. Em vista de las muchas variantes divergentes que se hallan en otras lenguas romances y en otras varias (vasco motz, cat. mus, esmussat, port. moucho, o mocho, fr. émoussé, alem. médio mutzen, port. e leonés mouco, etc.) parece ser palabra de creación expresiva (COROMINAS, 1998).

Machado (1987) também registra origem obscura para mocho e aventa a origem expressiva do termo. Já Cunha (1982) define mocho como 'sem cornos' 'que tem falta de algum membro'. Do cast. mocho, provavelmente de origem expressiva. O Dicionário da Real Academia Espanhola (2001) ratifica a origem incerta do termo e atribui-lhe, dentre outras, a seguinte acepção: "Dicho especialmente de un animal cornudo, de un árbol o de una torre: Que carece de punta o de la debida terminación". Silva (1813) define mocho como um adjetivo na acepção de "sem cornos, porque se cortarão [...] ou porque naturalmente os não tem". Essa obra não aponta a origem da palavra. Nascentes (1961) atribui-lhe origem incerta, "talvez criação expressiva”.

Todavia, apesar da origem incerta atribuída a esse item lexical por parte das obras consultadas, o testemunho de Cunha (1982) o avaliza como espanholismo e o habilita a pertencer ao corpus deste trabalho. 
2.1.5 Designações para "aquele inseto pequeno, de perninhas compridas, que canta no ouvido das pessoas, de noite" (QSL/88)

Para essa pergunta, foram registrados dois espanholismos: borrachudo e mosquito. Borrachudo foi assim considerado por sua associação com a "borracha", cujo étimo provém do espanhol de mesma grafia (CUNHA, 2010). Em Houaiss (2001), encontram-se como definição para essa variante tanto "dilatado como uma borracha" quanto "gordo, barrigudo", além de designação para insetos, podendo-se associar a característica de dilatação da borracha ao hábito alimentar do borrachudo, que vai ficando mais "gordo" à medida que suga o sangue de suas presas. Freire $(1939,1944)$ atribui-lhe a acepção de "espécie de mosquito hematófago da família das simúlidas, de picada muito dolorosa".

Para Nascentes (1961), borrachudo vem de "borracha, q. v., e suf. -udo. A fêmea deste mosquito pica os animais mamíferos, sugando-lhes o sangue até ficar rotunda como uma borracha cheia".

E como último espanholismo analisado sob a ótica léxico-semântica, apresenta-se mosquito, utilizado também para designar o "pernilongo", sendo ainda um nome genérico para várias espécies. Para Cunha (2010), advém do castelhano mosquiteiro e é o "inseto díptero da família dos culicídeos". Houaiss (2001) acrescenta-lhe tratar-se do "mosquito culicídeo (Culex pipiens), hematófago, de ampla disseminação por todas as regiões tropicais da terra e comum no interior das habitações humanas". A Real Academia Espanhola (2001) detalha ainda que "el macho vive de los jugos de lãs flores, y la hembra chupa la sangre de lãs personas y los animales de piel fina, produciendo con la picadura inflamación rápida acompañada de picor".

Silva (1813), por sua vez, apresenta uma definição para mosquito que abarca ainda borrachudo: "mosquíto, s. m. Insecto, que persegue os animáes, e homens, para sustentar do seu sangue, dos quaes há várias especies; v. g. moriçócas; maruîns, que vivem nos mangues, e são múi miúdos, e deixão ardor na ferida; borrachudos, que tem ventre como moscas, e fazem inchar onde mordem: de parede, \&c. tudo vulgar no Brasil”.

Assim, realizada a análise semântico-lexical das variantes catalogadas, a continuidade do trabalho dá-se com a abordagem diatópica dos registros de espanholismos.

\section{ANÁLISE DIATÓPICA}

Tendo em vista que a Dialetologia é o ramo da Linguística "que se ocupa da variação e da diversidade de usos" (CARDOSO, 2008, p. 16), esta parte do trabalho agrega, às questões léxico-semânticas, reflexões acerca dos usos dos itens lexicais analisados sob o viés dialetológico. Todavia, deve-se acrescentar que a Dialetologia vale-se da Geolinguística para o mapeamento de seus dados, como pode ser visualizado a partir deste momento.

Nesse sentido, a Carta Linguística I, a seguir, faz a apresentação do registro dos itens léxicos em análise, de acordo com a(s) localidade(s) em que foram documentados, ou seja, demonstra uma visão da distribuição diatópica dos espanholismos analisados.

Figura 2 Carta Linguística I - Distribuição diatópica dos espanholismos na região Centro-Oeste. 


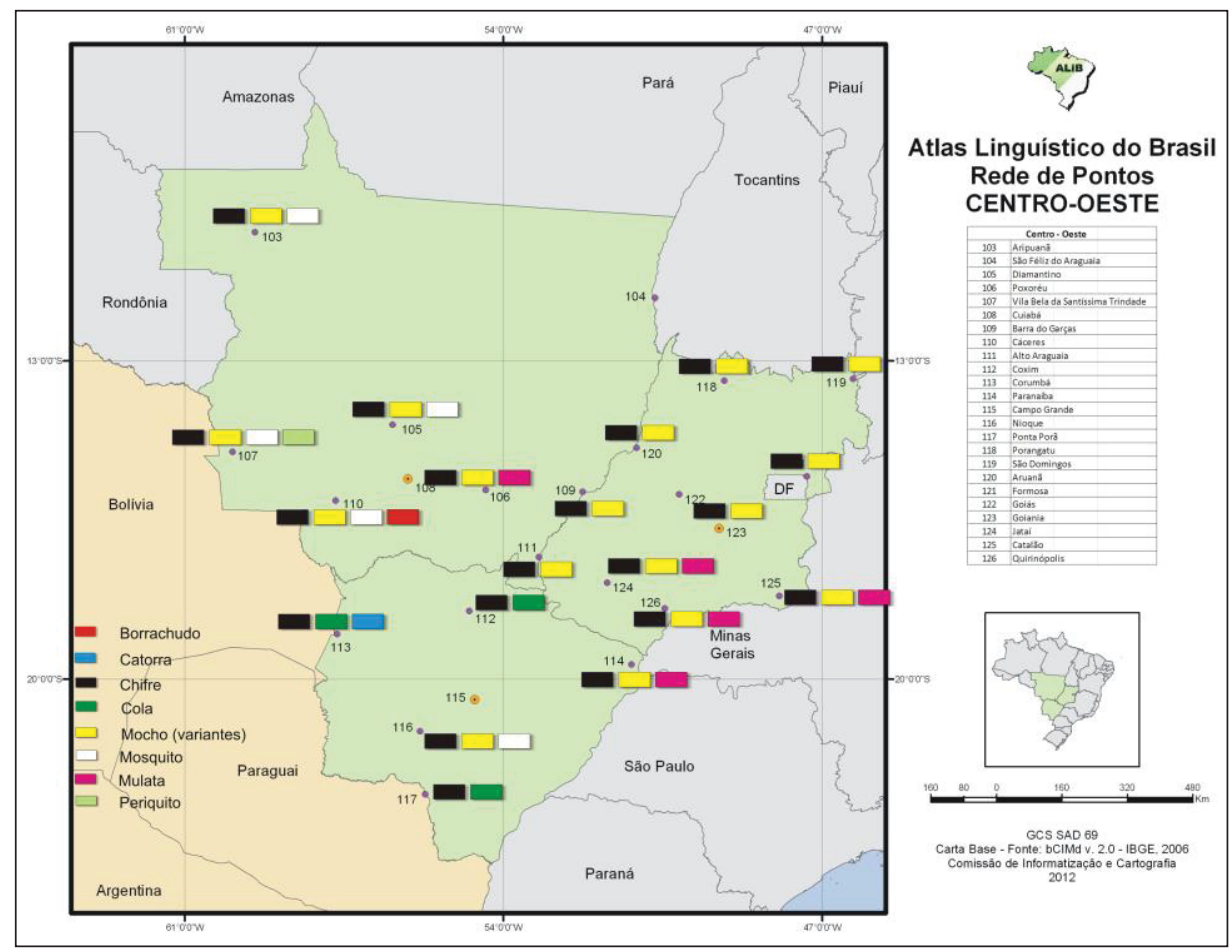

Fonte: bCimD (2012)

Observando-se as informações da Carta, confirma-se que a unidade lexical chifre foi mencionada em todas as localidades pesquisadas e por todos os informantes. Mocho/mucho, por sua vez, configurou-se como a segunda variante de maior abrangência espacial, não figurando apenas em Coxim, em Corumbá e em Ponta Porã (Mato Grosso do Sul).

Já em relação à mulata, nota-se um continuum geográfico em termos de distribuição diatópica, uma vez que o seu registro percorre o caminho de uma antiga rota das bandeiras, de Minas Gerais para o Estado de Mato Grosso, passando por Goiás e por Mato Grosso do Sul ${ }^{11}$. Pode-se inclusive inferir essa relação a partir da acepção dicionarizada do termo em Garcia (1943), que afirma que o mulato é aquele "que aluga mulas", animais utilizados pelos expedicionários para adentrar nos territórios.

Mosquito, por seu turno, foi documentado apenas nas cidades próximas à fronteira com a Bolívia e com o Paraguai, confirmando a relação entre proximidade geográfica e presença de espanholismos na fala dos habitantes entrevistados. Já cola registrou-se apenas em Mato Grosso do Sul (Ponta Porã, Corumbá - também áreas fronteiriças - e Coxim), o que pode evidenciar certo conservadorismo na fala dos sul-mato-grossenses, haja vista que a documentação da unidade lexical em Corominas (1998) data de 1220-50, podendo se caracterizar também como termo em vias de desuso, já que foi mencionada por duas informantes idosas e por apenas uma jovem corumbaense, de ascendência pantaneira e casada com um pescador, o que também pode ter influenciado sua fala, uma vez que a região pantaneira propicia a manutenção da norma linguística, dadas suas características geográficas de encerramento.

Já as formas catorra e periquito foram registradas em uma única localidade de Mato Grosso do Sul e de Mato Grosso - Corumbá e Vila Bela da Santíssima Trindade, respectivamente,

\footnotetext{
${ }^{11} \mathrm{Cf}$. Gressler et al., (2005) sobre as rotas das bandeiras que passaram pelo Centro-Oeste.
} 
cidades que se assemelham tanto pela proximidade com os países hispânicos quanto pela história, por se configurarem como localidades estrategicamente posicionadas para a manutenção do território nacional durante o período colonial, fundadas com vistas inclusive a defender o espaço brasileiro das invasões hispânicas. A variante lexical catorra pode ainda ser considerada um arcaísmo, tendo em vista ter sido registrada apenas na fala de uma informante idosa e ter sua dicionarização em Freire já em 1939, data do início da publicação dos volumes do Grande e Novíssimo Dicionário da Língua Portuguesa, e ainda ter sua abonação datada de 1693 em Houaiss (2001), como "cotorra".

Os dados examinados neste trabalho dão mostras, assim, da influência de determinantes extralinguísticos, como a localização geográfica, o contato com a língua espanhola e a história sociocultural no repertório lexical da população de uma região, neste caso dos habitantes do Centro-Oeste ao nomearem elementos relacionados à fauna.

Frente ao exposto, nota-se então que as línguas em contato num dado espaço geográfico contribuem para particularizar o léxico em uso por uma comunidade linguística, uma vez que "é no âmbito de um grupo social que a norma se instaura, é disseminada ou ficar confinada a determinados espaços geográficos, dependendo das condições socioculturais desse grupo" (ISQUERDO, 2006, p.22).

\section{ALGUMAS CONSIDERAÇÕES FINAIS}

A herança espanhola no português brasileiro é perceptível em diversas áreas semânticas e se manifesta tanto no vocabulário comum veiculado em todas as regiões do Brasil quanto no léxico regional em áreas de maior contato com países hispânicos, o que fica evidente também na língua falada pelos habitantes do Brasil Central e no Centro-Oeste, mesmo depois de mais de 200 anos de dominação portuguesa.

Trocas culturais entre brasileiros e cidadãos de países da América espanhola, seja pelo legado histórico, seja pela aproximação geográfica, refletem-se nas escolhas lexicais dos falantes do Centro-Oeste. Os espanholismos recolhidos a partir das entrevistas realizadas pelos pesquisadores do Projeto ALiB com habitantes dos três Estados da região Centro-Oeste ilustram isso: se, por um lado, foram catalogadas unidades lexicais de base espanhola já incorporadas ao léxico do português, como periquito, chifre, mosquito, por outro, a pesquisa documentou determinados itens lexicais que evidenciam usos regionais: mulata, catorra, cola, mocho/mucho, borrachudo.

Também se verificou que o registro de alguns designativos pode revelar marcas de conservadorismo na fala de alguns usuários da língua, como o uso de cola para nomear o "rabo do boi/cavalo", e que tem seus primeiros registros ainda antes do descobrimento das Américas.

Evidencia-se ainda, neste trabalho, que a influência da cultura espanhola perpassa as fronteiras da culinária e das representações culturais como o folclore e a dança, fazendo-se presente também no léxico relacionado a outras áreas semânticas, dentre elas, a fauna, como ficou evidenciado no estudo que deu origem a este artigo: 04 registros em Goiás, 07 em Mato Grosso e 07 em Mato Grosso do Sul, inclusive com maior ocorrência de espanholismos em cidades próximas à fronteira seca com a Bolívia (04 - Vila Bela da Santíssima Trindade e Cáceres, MT). 
Enfim, essas considerações mostram especialmente a importância das pesquisas geolinguísticas para o estudo da inter-relação entre léxico e sociedade, confirmada pelo uso de designativos de base espanhola, além da indígena e africana, para nomear elementos nacionais da fauna brasileira.

\section{REFERÊNCIAS}

BIDERMAN, M. T. de C. Teoria linguística: linguística quantitativa e computacional. Rio de Janeiro, RJ: Livros Técnicos e Científicos, 1978.

CARDOSO, S. A. M. Reflexões sobre a Dialectologia. In: ISQUERDO, Aparecida Negri (Org.). Estudos geolingüisticas e dialetais sobre o português. Campo Grande: Editora UFMS, 2008. P. 15-31.

. Geolinguística. Tradição e Modernidade. São Paulo: Parábola Editorial, 2010.

CAVERO, D. O. Dicionario português-Español/español-portugués. Barcelona: Editorial Ramon Sopena, 1977.

COROMINAS, J. Breve diccionario etimológico de la lengua castellana. $3^{\mathrm{a}}$ ed. Madrid: Gredos, 1998.

COSERIU, E. Lições de linguística geral. Tradução: Evanildo Bechara. Rio de Janeiro: AO Livro Técnico, 1980.

CUNHA, A. G. da. Dicionário etimológico Nova Fronteira da Língua Portuguesa. 2 ed. Rio de Janeiro, RJ: Nova Fronteira, 1982.

. Dicionário etimológico da língua portuguesa. 4 ed. Rio de Janeiro: Lexikon, 2010.

DICK, M. V. de P. do Amaral. Inter-relação léxico e cultura na América Indígena. Estudo de Caso. In: Acta Semiótica et Linguística (SBPL), São Paulo, SP, v.8, p. 295-308, 2000.

FERREIRA, A. B. de H. Novo Dicionário Aurélio da Lingua Portuguesa. Versão 5.0, Curitiba, PR: Editora Positivo, 2004.

FREIRE, L. Grande e novíssimo dicionário da língua portuguesa. Rio de Janeiro, RJ: A noite S.A. Editora, 1939, 1944 vol. II B e D e IV J-P.

GARCIA, H. de. Dicionário Espanhol português. Porto Alegre, RS: Livraria do Globo, 1943.

GRESSLER, L. A.; VASCONCELOS, L. M.; SOUZA, Z. P. de. História e geografia de Mato Grosso do Sul. São Paulo, SP: FTD, 2005.

HOUAISS, A. Dicionário Eletrônico Houaiss da Língua Portuguesa, versão 1.0. Rio de Janeiro, RJ: Editora Objetiva, 2001.

ISQUERDO, A. N. Achega para a discussão do conceito de regionalismos no Português do Brasil. In: Alfa: Revista de Linguística UNESP. v. 50, n 2. São Paulo: UNESP, 2006, p. 9-24.

LARA, L. F. El concepto de norma em Linguística. México: El Colegio de México, 1976.

MACHADO, J. P. Dicionário etimológico da Língua Portuguesa. 4 ed. Lisboa: Livros Horizonte, 1987.

NASCENTES, A. Dicionário etimológico resumido. Rio de Janeiro: INL / MEC / Seção da Enciclopédia e do Dicionário, 1961. 
ORTÊNCIO, W. B. Dicionário do Brasil Central. Subsídios à Filologia. São Paulo: Editora Ática S.A., 1983.

REAL ACADEMIA ESPAÑOLA. Diccionario de la lengua española. 22 ed. Madrid: 2001. Disponível em: <http://www.wordreference.com/es/en/frames.asp?es=columna $>$. Acesso em: 15 jun. 2013.

SAIKI, P. T. O. GUIDO, L. de F. E. CUNHA, A. M. de O. Etnoecologia, etnotaxonomia e valoração cultural de Psittacidae em distritos rurais do Triângulo Mineiro, Brasil. In: Revista Brasileira de Ornitologia. Vol. 17 (01), mar 2009. p 41-52. Disponível em: $<$ http://www.ararajuba.org.br/sbo/ararajuba/artigos/Volume171/rbo171art5.pdf $>$. Acesso em: 15 jun. 2013.

SANTANA, A. P.; ISQUERDO, A. N. Um estudo dos espanholismos no atlas linguístico de Mato Grosso do Sul. In: ISQUERDO, A. N.; HORA, D. da (Org.) ABRALIN em cena: Mato Grosso do Sul. João Pessoa, PB: Ideia, 2008, p. 10-17. Meio eletrônico.

SIGRIST, M. Chão batido: a cultura popular de Mato Grosso do Sul: folclore, tradição. Campo Grande, MS: Editora UFMS, 2000.

SILVA, A. de M. Diccionario da Lingua Portugueza. Tomo I. Lisboa: Typographia Lacérdina, 1813. In: FREIRE, L. Revista de Língua Portuguesa, $\mathrm{n}^{\circ}$ 15, ano III, janeiro de 1922.

Recebido: $15 / 06 / 2013$

Aceito: $31 / 08 / 2013$ 